\title{
Perspectives of New Decision Making Models of Processes Synchronization in Distributed Systems
}

\author{
David L. La Red Martinez ${ }^{1}$, Julio C. Acosta ${ }^{2}$ \\ ${ }^{1}$ Northeast National University, Computer Science Department, 9 de julio 1449 (3400), Corrientes, Argentine \\ laredmartinez@gigared.com \\ ${ }^{2}$ Northeast National University, Mathematics Department, 9 de julio 1449 (3400), Corrientes, Argentine \\ Irmdavid@exa.unne.edu.ar
}

\begin{abstract}
In the groups of processes in distributed systems is necessary to make decisions based on agreements; these processes may operate in distributed teams; processes may require the use of shared resources in the form of mutual exclusion. The following question arises: what decision models will be necessary to generate incorporating the cognitive perspective (mechanisms of self-regulation, autonomy, referential circularity, etc., should take into account; it is required to incorporate these aspects through variables and procedures added to the variables and procedures of the classical computer science; new models that improve the performance of the classics, incorporating new concepts, variables and procedures, will generate [18], [12], [20], [21], [22], [58]) to classical models, which transcend the traditional approach to the computer science? (are considered classical models for access to data structures shared in the form of mutual exclusion using critical regions (from memory), the centralized algorithm, the Lamport distributed algorithm, improved by Ricart and Agrawala, token ring algorithm, among others [49], [51], [52], [54], [55], [56]).
\end{abstract}

\section{Indexing terms/Keywords}

Operating systems - critical regions - mutual exclusion - communication between groups of processes - aggregation operators.

\section{Academic Discipline And Sub-Disciplines}

Computer science

\section{SUBJECT CLASSIFICATION}

Library of Congress Classification

\section{TYPE (METHOD/APPROACH)}

Quasi-Experimental

\section{Council for Innovative Research}

Peer Review Research Publishing System

Journal: International Journal of Management \& Information Technology

Vol. 9, No. 1

editor@cirworld.com

www.cirworld.com, member.cirworld.com 


\section{INTRODUCTION}

\section{Presentation}

The proliferation of computer systems, many of them distributed, in which there are multiple processes that cooperate to achieve a particular function, makes it necessary to have decision making models allowing the processes involved in different groups of processes, make decisions that are required different levels of agreement, especially when it's access to shared computing resources and the system should auto-regulate the form of such sharing.

Access to the critical memory regions by different processes, which may be running on the same computer or distributed teams, where access to critical regions must be in exclusive access mode and with the consent of the other processes in the group is especially significant.

Examples of the above are in [54], [55], where they are described the main synchronization algorithms in distributed systems, in [1], which presents efficient and faults tolerant solution for distributed mutual exclusion problem, in [49], [6] and [33], where algorithms are presented to manage mutual exclusion on computers networks, in [52], which outlined the main algorithms for distributed process management, distributed global states and distributed mutual exclusion.

\section{Research area}

Decision models currently available and generally applicable in distributed systems are based on permissions exchange algorithms, they are trying to reach an agreement of all involved processes to perform certain actions, such as access to an area of shared memory that must be accessed in the form of mutual exclusion.

It is very important to study the application of decision models for making group decisions, that incorporate cognitive concepts of cybernetics in general and second order cybernetics in particular, in the context of complex systems selfregulated.

It is very important to study the mechanisms of self-regulation of the self-regulated systems existing in the specialized literature, especially the mechanisms of complex systems, in the context of the second order cybernetics, in order to incorporate them into the decision models of groups of distributed processes, which must decide how to use shared resources.

It is considered that such groups of processes would improve their performance through the decision models to be developed incorporating concepts of second order cybernetics and mechanisms of self-regulation in the decisionmaking process.

It is not intended to obtain a general model applicable to any self-regulated system; attempts to incorporate mechanisms of self-regulation and concepts of second order cybernetics to the classical algorithms of computer science, to generate new models of decision making in distributed process groups; shall be considered the application of imputation methods for cases of missing data, for example as a result of problems in communications between processes; fuzzy variables will be used to support situations where it is not possible or desirable to express precise values.

\section{Problems}

In processing distributed computer systems frequently it is necessary the processes acting in groups to make decisions based on the agreement; these processes may operate on a same computer or several interconnected distributed teams; decisions which should achieve some level of agreement may be related to specific activity that does not require the use of shared resources in the form of mutual exclusion, or the realization of particular activity that requires the use of shared resources in the form of mutual exclusion, for which the requirements of levels of agreement are generally higher than for the previous case.

As a result of the foregoing, the following question arises: what are the new decision models that will be necessary to develop incorporating the cognitive perspective to the classic models for decision making in groups of processes, transcending the traditional approach of the computer science?

We will have to develop new decision models for the following types of situations: a) when does not undertakes the use of shared resources and agreement requirements are not strict; b) when does not undertake the use of shared resources and agreement requirements are strict; c) when it is committed to the use of shared resources and the agreement requirements are not strict; $d$ ) when it is committed to the use of shared resources and the agreement requirements are strict?.

\section{OBJECTIVES AND HYPOTHESES BASED ON THE NEED TO PUT FORWARD Objectives}

The general objective is to generate decision models from the cognitive perspective to decision-making in groups of processes, transcending the traditional approach of computing sciences, based on the principles of second order cybernetics, complex systems and self-regulation. 


\section{Hypothesis}

The principles of second order cybernetics, complex systems and self-regulation, make it possible to develop decision models from the cognitive perspective to decision-making in groups of processes, transcending the traditional approach to the computer science whereas the possibility of imputation of missing data and the use of fuzzy variables, using the OWA family operators, generating specific operators to each of the above situations.

\section{KNOWLEDGE STATE OF AREAS THAT WOULD CONTRIBUTE TO NEW DECISION MODELS}

Below are the main contributions to the knowledge state, in the different areas related to proposal.

\section{Cybernetics}

[2] expressed the importance of context in communication. It presents a systemic and interdisciplinary vision of communicative processes that conceives the communicational processes with a circular and evolutionary character, where feedback is of decisive importance. [18] is a follow-up of the evolution of concepts of Cybernetics on the basis of the pioneers, such as Wiener, von Neumann, von Forster, von Bertalanffy and Ashby, and shown that systemiccybernetic language is a developed conceptual network. [23] expresses the computational paradox, which means that the application of computational models and methods has led to understand in what human beings do not resemble computers. [57] introduces a framework based on Bayesian theory to model the inductive learning and reasoning as statistical inferences about structured representations of knowledge. [60] expresses that if all mind states (such as beliefs, thoughts and concepts) can be described as operations on symbolic representations, the mental activity (reasoning, planning and decision making) is equivalent to the execution of an algorithm. [65] defines the main concepts of cybernetics; expressed that cybernetics is any field of command and communication theory, both on the machine, as in the animal. He also claims that cybernetics aims to find common elements to the operation of machines and the nervous system of man and to develop a theory that encompasses the entire field of the control and communication in machines and living organisms.

\section{Self-regulating complex systems and second-order cybernetics}

[12] presents notions such as decentralization, emergency, dynamic systems, recognition of patterns, adaptive conduct, etc., applied to robotics, ethology, economy, etc., all in order to present the image of embodied and embedded mind as an evolution from the connectionist mind. [17] studied the relationship between the observer and the observed system, showing that these two systems are inseparable. Explores the relationship between reality and community. In 1958, Foerster revised the approaches of Wiener on cybernetics and proposed a new approach, typical of complex systems, defined as second-order cybernetics. [20], [21] and [22] studying complex systems in their basic aspects, its main concepts and the construction of knowledge from the perspective of complex systems. [58] presents the main concepts of enaction and emergence, and an overview of the evolution of the central concepts of cybernetics.

\section{Autonomic computing and cognitive processes}

[11] presents a mathematical and cognitive model that describes the resolution of problems as a cognitive process. [42] presents a new learning algorithm for fuzzy cognitive maps, based on the application of a swarm intelligence algorithm, called PSO (Particle Swarm Optimization). [53] presents a Real-Time Process Algebra (RTPA) developed to describe complex behaviors of humans and software systems. Presents a group of 280 grammatical rules and recognition techniques. [64] describes a Layered Reference Model of the Brain (LRMB) and its cognitive mechanisms and processes. It proposes a Real-Time Process Algebra (RTPA) to describe formally and rigorously autonomic computing systems and cognitive behaviors. [62] and [63] presents a model of cognitive goal processes of the mind. Cognitive processes are defined in a cognitive goal level in the LRMB (Layered Reference Model of the Brain) using the RTPA (Real-Time Process Algebra) and OAR (Object-Attribute-Relation) model for the representation and manipulation of internal information of cognitive goal processes.

\section{Cognitive computation}

[15] discusses the application of mental models to the human - computer interaction. [40] studies the union of neuroscience, supercomputing and nanotechnology to discover, prove and deliver brain algorithms. Non - von Neumann computer architectures, programming paradigms and applications that integrate, analyze and act based on large amounts of data from many sources at the same time are used.

\section{Communication in distributed systems}

[4] shows a protocol of reliable communication in the presence of failures, from the perspective of the computer science. [5] presents a multicast communication protocol for groups of processes in the atomic mode, from the perspective of the computer science. [29] presents reliable communication protocols in broadcast mode, from the perspective of the computer science. [54], [55] and [56] describe the main communication algorithms in distributed systems (classical algorithms of computer science). [51] shows the main algorithms for distributed coordination and management of the mutual exclusion (classical algorithms of computer science). 


\section{Data imputation methods}

[30] describe methods of multiple imputation of data to resolve the problem of missing data needed for decisionmaking. [41] and [44] describe general and specific application imputation methods.

\section{Synchronization in distributed systems}

[1] shows an efficient and fault tolerant solution, for distributed mutual exclusion problem, from the perspective of the computer science. [49], [6] and [33] presented some algorithms to manage mutual exclusion in computer networks, according to the computer science. [52] details the main algorithms for the computer science for the distributed management of processes, distributed global states and distributed mutual exclusion. [54] and [55] shows the main synchronization algorithms in distributed systems (classical algorithms of computer science).

\section{Decision support systems}

[14] presents a group decision model with the use of OWA (Ordered Weighted Averaging) family aggregation operators. [43], [46] and [45] discusses in-group aggregation (by majority) operators seeking representation of most. [7] studies the application of decision-making linguistic methods to deal with the quality of service evaluation problems. [16] studied the fuzzy preference modelling for multi-criteria decision support. [19] presents the use of OWA (Ordered Weighted Averaging) aggregation operator's family for decision-making. [39] presents the ANP (Analytic Network Process) and its application to a specific case of decision-making. The NPA is based on the MCDA (Multiple Criteria Decision Analysis). [24] presents methodologies to solve problems in the presence of multiple attributes and criteria. [36] studying decision support systems. [43], [46], [47] and [45] analyzes group aggregation operators (by majority) in seeking the representation of the majority. [50] shows the AHP (Analytic Hierarchy Process) for decisionmaking.

\section{Group decision-making}

[3] analyzes the aggregation of linguistic labels and measures of consensus for the autocratic decision-making using recommendations. [34], [25], [26] and [27] present group decision-making models of fuzzy linguistic information. [8], [9] and [10] presented several usable aggregation operators for decision-making in groups. [13] shows the combination of numerical and linguistic information in group decision-making. [28] and [25] studies, respectively, group decision-making using OWA linguistic operators and diffuse 2-tuple linguistic representation model for computing with words. [59] describes a consensus support system model for group decision-making problems with multi-granular linguistic preference relations. [31] presents the WKC-OWA operator to aggregate information in democratic decision problems. [32] shows a group decision-making model using linguistic labels, and a new expression form of decision-makers preferences. [35], [37] and [38] show group decision-making with multi-objectives, the treatment of heterogeneous information in engineering evaluation processes and engineering systems. [43], [46] and [47] discusses majority aggregation operators and its applications to group decision-making. [66] and [67] show and study OWA (Ordered Weighted Averaging) operators applied to multi-criteria decision-making. [68] and [69] describes the OWA operators and their application in multi-agent decision-making.

\section{Decision making and cognitive processes}

[48] shows different probabilistic cognition models, using cognitive science, computer science, mathematics and statistics. [64] shows a formal description of decision-making cognitive processes, on the basis the model LRMB (Layered Reference Model of the Brain). The decision-making cognitive process is modeled as a sequence of decisions based on cartesian product. It is a rigorous description of decision-making process with the RTPA (RealTime Process Algebra).

\section{OVERVIEW OF THE METHODOLOGY THAT WILL BE USED}

The research to be carried out shall be theoretical type in the stage of development of decision models. Once defined theoretically decision models, it will proceed to validation, your results will be compared with the results of the computer science models usually used in operating systems. As result of the analysis of the obtained data, it may be necessary to modify the proposed decision models, which will begin a new cycle of validations.

\section{PROPOSED INITIAL DATA STRUCTURES}

It will use a data arrays system with the following premises and structures.

It has groups of processes, across process nodes; processes access critical shared resources in the form of distributed mutual exclusion; you have to determine what will be the priorities for allocating resources to processes (will only be alternative assignment available resources, i.e. not assigned to processes):

- Permission to access the shared resources of a node not depend only if nodes are using them or not, but the value of aggregation of opinions (priorities) of the different nodes regarding access to shared resources (alternatives). 
- Opinions (priorities) of the nodes, about granting access to shared resources (alternatives), will depend on variables representing the state of each node. Taking into account the requirements of resources of each process in each group, each node must express its priorities for the allocation of shared resources.

Nodes that host processes: $1, \ldots, n$.

Processes hosted in each of the $n$ nodes: $1, \ldots, p$.

Distributed process groups: $1, \ldots, g$.

Size of each of the $g$ groups of processes: $1, \ldots, t$.

Critical resources shared in the form of distributed mutual exclusion, available at each of the $n$ nodes: $1, \ldots, r$.

Possible states of each of the $p$ processes:

- $\quad$ Group to which belongs the process (0 means independent process).

- Waiting for a resource shared with his group of processes.

- Waiting for a resource not shared with his group of processes.

- $\quad$ Running with permission to access a resource shared with its process group.

- Running without permission to access a resource shared with its process group.

- Inactive.

Status of each of the $n$ nodes:

- Number of processes.

- Priorities of processes.

- $\quad$ CPU usage.

- Use of main memory.

- Use of virtual memory.

- Status of each of the $r$ critical resources, shared in the form of distributed mutual exclusion in the node:
- Assigned to a local process.
- Assigned to a remote process.
- Available.

- $\quad$ Predisposition (nodal priority) to grant access to each of the $r$ shared critical resources (alternatives) in the form of distributed mutual exclusion (result of consideration of the variables representing the state of the node, for each existing share critical). A tuple is obtained for each of the $n$ nodes, each tuple will contain $r$ values (nodal priorities) to share critical resources.

Systems global status:

- Number $g$ of groups of processes and size $t$ (number of processes) of each group.

- Percentages of consensus required to grant access to each of the $r$ critical resources available in each of the $n$ nodes.

- Predisposition (global priority) to grant access to each of the $r$ shared critical resources (alternatives), in the distributed mutual exclusion form, which will result from the aggregation of the nodal priorities for each existing share critical resource (alternative). A tuple $r$ of normalized values (global priorities) is obtained to share critical resources.

- Access decision to $r$ critical resources, because of contrasting the normalized global priorities, to share these resources, with the percentages of consensus required to grant the respective accesses.

- The system global status must be updated repeatedly, while $p$ processes require access to $r$ shared resources.

The system is self regulates repeatedly considering local nodes status and the global system status. Updated local status because of the evolution of their processes, and access to your critical resources, taking into account the overall status of the system: distributed system where running groups of processes that have access to critical resources, notes to himself, and produces decisions of access to resources that modify the system global status and rearranged it repeatedly.

\section{Processing and data analysis}


Simulations will be processed with the proposed decision models and classical computational decision models. We will analyze the behavior of models for the same workloads and resources consumption. The proposed models will be iteratively modified trying to achieve a performance at least equivalent to the classical computational models.

Shall be considered the situation of missing data, and the possibility of using imputation methods to complete missing data.

\section{RESULTS}

It has suggested the need of new decision-making models for decision making in distributed processes groups that share resources.

Areas of knowledge that could help the new decision models have shown.

A first approach to the data structures that could be used in new decision models has shown.

\section{FINAL CONSIDERATIONS}

\section{Conclusions}

The study of the main concepts of cognitive sciences suggests that the application of the same will allow to develop decision models for groups of processes that interact being able to share resources.

These new decision models could be overcome to the classical computer sciences models, achieving a better overall performance, to make decisions considering details and a more global vision of the problems.

The new models should consider the possibility of imputation of missing data (due to failures in nodes or links) and fuzzy variables, using the family of OWA operators, creating specific aggregation operators to each types of situations considered.

The developed models will be validated and adjusted by comparing their results with the commonly used models.

\section{Future works}

The specific objectives are to generate decision models from the cognitive perspective to decision-making in groups of processes, transcending the traditional approach of the computer science.

Base the new models on the principles of second order cybernetics, complex systems and self-regulation.

The use of modifications of the OWA family operators (Yager, 1988, 1993) will be studied, for the following types of situations:

- Shared resources are not used and the consensus demands are not strict.

- Shared resources are not used and consensus requirements are strict.

- $\quad$ Shared resources are used and the consensus demands are not strict.

- Shared resources are used and the consensus demands are strict.

You must compare, whereas the performance, the new models with the known and generally accepted computer science models.

\section{ACKNOWLEDGMENTS}

$\mathrm{He}$ is grateful for the funding of the research project "Decision Models for the Processes Synchronization in Distributed Systems", accredited by Science and Technology General Secretariat from the UNNE (Northeast National University), code 12F003, resolution No. 960/28-11-12, effective 01/01/2013-12/31/2016.

\section{REFERENCES}

[1] Agrawal, D.; Abbadi, A. E. An efficient and fault-tolerant solution of distributed mutual exclusion. ACM Trans. on Computer Systems, USA, v. 9, p. 1-20, 1991

[2] Bateson, G. Pasos Hacia Una Ecología de la Mente. Argentina: Planeta-Carlos Lohlé, 1991.

[3] Ben-Arieh, D.; Chen, Z. Linguistic-labels aggregation and consensus measures for autocratic decision making using group recommendations. IEEE Transactions on Systems, Man, and Cybernetics Part A: Systems and Humans, v. 36, n. 3, p. 558-568, 2006.

[4] Birman, K. P.; Joseph, T. Reliable communication in the presence of failures. ACM Trans. on Computer Systems, v. 5, p. $47-76,1987$.

[5] Birman, K. P.; Schiper, A.; Stephenson, P. Lightweight causal and atomic group multicast. ACM Trans. on Computer Systems, USA, v. 9, p. 272-314, 1991. 
[6] Cao, G.; Singhal, M. A delay-optimal quorumbased mutual exclusion algorithm for distributed systems. IEEE Transactions on Parallel And Distributed Systems, USA, v. 12, n. 12, p. 1256-1268, 2001.

[7] Chen, C. T. Applying linguistic decision-making method to deal with service quality evaluation problems International Journal of Uncertainty, Fuzzyness and Knowledge-based Systems, v. 9, p. 103-114, 2001.

[8] Chiclana, F.; Herrera, F.; Viedma, E. H. The ordered weighted geometric operator: Properties and application. Proc. of 8th International Conference on Information Processing and Management of Uncertainty in Knowledgebased Systems, España, p. 985-991, 2000.

[9] Chiclana, F.; Herrera, F.; Viedma, E. H. Integrating multiplicative preference relations in a multipurpose decision making model based on fuzzy preference relations. Fuzzy Sets and Systems, v. 112, p. 277-291, 2001.

[10] Chiclana, F. et al. Induced ordered weighted geometric operators and their use in the aggregation of multiplicative preferences relations. International Journal of Intelligent Systems, v. 19, p. 233-255, 2004.

[11] Chiew, V.; Wang, Y. Formal description of the cognitive process of problem solving. Proceedings of the Third IEEE International Conference on Cognitive Informatics (ICCl'04), USA, 2004.

[12] Clark, A. Estar Ahí - Cerebro, Cuerpo y Mundo en la Nueva Ciencia Cognitiva. España: Ediciones Paidós lbérica S. A., 1999.

[13] Delgado, M. et al. Combining numerical and linguistic information in group decision making. Information Sciences, v. 107, p. 177-194, 1998.

[14] Doña, J. M. et al. A system based on the concept of linguistic majority for the companies valuation. Revista EconoQuantum, México, v. 8, n. 2, p. 121-142, 2011.

[15] Ehrlich, K. The Essential Role of Mental Models in HCl. Cambridge, MA, USA: IBM Research Division, 2007. (IBM Research Report).

[16] Fodor, J. C.; Roubens, M. Fuzzy Preference Modelling and Multicriteria Decision Support. Dordrecht: Kluwer, 1994.

[17] Foerster, H. V. Las Semillas de la Cibernética. España: Gedisa, 1996. (2 edición).

[18] François, C. Systemics and cybernetics in a historical perspective. Systems Research and Behavioral Science, USA, n. 16, p. 203-219, 1999.

[19] Fullér, R. OWA operators in decision making. En Carlsson, C. ed. Exploring the Limits of Support Systems, TUCS General Publications, Turku Centre for Computer Science, n. 3, p. 85-104, 1996

[20] García, R. Conceptos básicos para el estudio de sistemas complejos. En Enrique Left (Coord.), Los Problemas del Conocimiento y la Perspectiva Ambiental del Desarrollo, Siglo XXI, México, n. 16, p. 85-124, 1986.

[21] García, R. El conocimiento en construcción. De las Formulaciones de Jean Piaget a la Teoría de los Sistemas Complejos, Gedisa Editorial, España, 2000.

[22] García, R. Sistemas complejos. Conceptos, Métodos y Fundamentación Epistemológica de la Investigación Interdisciplinaria, Gedisa Editorial, España, 2006.

[23] Gardner, H. La Nueva Ciencia de la Mente. España: Ediciones Paidós, 1996. (2 reimpresión).

[24] Greco, S.; Matarazzo, B.; Slowinski, R. Rough sets methodology for sorting problems in presence of multiple attributes and criteria. European Journal of Operational Research, v. 138, p. 247-259, 2002.

[25] Herrera, F.; Martínez, L. A 2-tuple fuzzy linguistic representation model for computing with words. IEEE Transactions on Fuzzy Systems, v. 8, n. 6, p. 746-752, 2000.

[26] Herrera, F.; Viedma, E. H. Linguistic decision analysis: Steps for solving decision problems under linguistic information. Fuzzy Sets and Systems, v. 115, p. 67-82, 2000.

[27] Herrera, F.; Viedma, E. H.; Verdegay, J. L. Direct approach processes in group decision making using linguistic OWA operators. Fuzzy Sets and Systems, v. 79, p. 175-190, 1996.

[28] Herrera, F.; Viedma, E. H.; Verdegay, J. L. A model of consensus in group decision making under linguistic assessments. Fuzzy Sets and Systems, v. 78, p. 73-87, 1996.

[29] Joseph, T. A.; Birman, K. P. Reliable Broadcast Protocols, en Distributed Systems. Mullender. USA: Mullender, S. (Ed). ACM Press, 1989.

[30] Kennickell, A. B. Multiple Imputation In The Survey Of Consumer Finances. USA: Board of Governors of the Federal Reserve System. Joint Statistical Meetings, 1998

[31] La Red Martínez, D. L.; Doña, J. M.; Peláez, J. I.; Fernandez, E. B. WKC-OWA, a new Neat-OWA operator to aggregate information in democratic decision problems. International Journal of Uncertainty, Fuzziness and Knowledge-based Systems,World Scientific Publishing Company, Francia, p. 759-779, 2011. 
[32] La Red Martínez, D. L.; Peláez, J. I.; Doña, J. M. A decision model to the representative democracy with expanded vote. Pioneer Journal of Computer Science and Engineering Technology, India, p. 35-45, 2011.

[33] Lodha, S.; Kshemkalyani, A. A fair distributed mutual exclusion algorithm. IEEE Trans. Parallel and Distributed Systems, USA, p. 537-549, 2000.

[34] Lorite, F. J. C. Nuevos modelos de toma de decisión en grupo con información lingüística difusa. España: Universidad de Granada, 2008. (Tesis doctoral).

[35] Lu, J. et al. Multi-objective Group Decision Making: Methods, Software and Applications with Fuzzy Set Technology. London: Imperial College Press, 2007.

[36] Marakas, G. Decision Support Systems. New Jersey, USA: Prentice Hall, 2002.

[37] Martínez, L. et al. Dealing with heterogeneous information in engineering evaluation processes. Information Sciences, v. 177, n. 7, p. 1533-1542, 2007.

[38] Martínez, L.; Liu, J.; Yang, J. B. A fuzzy model for design evaluation based on multiple-criteria analysis in engineering systems. International Journal of Uncertainty, Fuzziness and Knowledge-based Systems, v. 14, n. 3, p. 317-336, 2006.

[39] Melón, M. G. et al. Farmland appraisal: An analytic network process (anp) approach. MCDM, Greece, 2006.

[40] Modha, D. S. et al. Cognitive computing. Communications of the ACM, v. 54, n. 8, p. 62-71, 2011.

[41] Nguyen, L. N.; Scherer,W. T. Imputation techniques to account for missing data in support of intelligent transportation systems applications. Research Report No. UVACTS-13-0-78, USA, 2003.

[42] Papageorgiou, E. I. et al. Fuzzy cognitive maps learning using particle swarm optimization. Journal of Intelligent Information Systems, USA, v. 25, n. 1, p. 95-121, 2005.

[43] Peláez, J. I.; Doña, J. M. Majority additiveordered weighting averaging: A new neat ordered weighting averaging operators based on the majority process. International Journal of Intelligent Systems, USA, v. 18, n. 4, p. 469$481,2003$.

[44] Peláez, J. I.; Doña, J. M.;La Red Martínez, D. L. Fuzzy imputation method for database systems. En Galindo, J. (Ed.). Handbook of Research on Fuzzy Information Processing in Database. Hershey. Information Science Reference, USA, 2008.

[45] Peláez, J. I.; Doña, J. M.; La Red Martínez, D. L. A mix model of discounted cash-flow and OWA operators for strategic valuation. Revista Interactive Multimedia and Artificial Intelligence - Special Issue On Business Intelligence And Semantic Web, España, v. 1, n. 2, p. 20-25, 2009.

[46] Peláez, J. I. et al. Majority opinion in group decision making using the QMA-OWA operator. Proceeding of ESTYLF, p. 449-454, 2004.

[47] Peláez, J. I.; Doña, J. M.; Gómez Ruiz, J. A. G. Analysis of OWA operators in decision making for modelling the mayority concept. Applied Mathematics and Computation, v. 186, p. 1263-1275, 2007.

[48] Probabilistic Models of Cognition: The Mathematics of Mind. USA: IPAM (Institute For Pure And Applied Mathematics. University of California, Los Angeles), 2007. Available in: <http://www.ipam.ucla.edu/programs/gss2007/>.

[49] Ricart, G.; Agrawala, A. K. An optimal algorithm for mutual exclusion in computer networks. Commun. of the ACM, v. 24, p. 9-17, 1981.

[50] Saaty, T. L. The Analytic Hierarchy Process. USA: MacGraw Hill, 1980.

[51] Silberschatz, A.; Galvin, P. B.; Gagne, G. Fundamentos de Sistemas Operativos. España: Mac-Graw Hill, 2006. (7 Edición).

[52] Stallings,W. Sistemas Operativos. España: Pearson Educación S.A, 2005. (5 Edición).

[53] Tan, X.; Wang, Y.; Ngolah, C. F. Specification of the rtpa grammar and its recognition. Proceedings of the Third IEEE International Conference on Cognitive Informatics (ICCl'04), USA, 2004.

[54] Tanenbaum, A. S. Sistemas Operativos Distribuidos. México: Prentice - Hall Hispanoamericana S.A., 1996.

[55] Tanenbaum, A. S. Sistemas Operativos Modernos. México: Pearson Educación S. A., 2009. (3 Edición).

[56] Tanenbaum, A. S.; Steen, M. V. Sistemas Distribuidos - Principios y Paradigmas. México: Pearson Educación S. A., 2008. (2 Edición).

[57] Tenenbaum, J. B.; Griffiths, T. L. and Kemp, C. Theory-Based Bayesian Models Of Inductive Learning And Reasoning. Elsevier. Special Issue: Probabilistic Models Of Cognition. TRENDS in Cognitive Sciences Vol.10 No.7. USA, 2006 
[58] Varela, F. J. Conocer - Las Ciencias Cognitivas: Tendencias y Perspectivas - Cartografía de las Ideas Actuales. España: Gedisa Editorial, 1990.

[59] Viedma, E. H. et al. A consensus support system model for group decision-making problems withmultigranular linguistic preference relations. IEEE Transactions on Fuzzy Systems, v. 13, n. 5, p. 644-658, 2005.

[60] Wainstein, M. Comunicación. Un Paradigma de la Mente. Argentina: JCE Ediciones, 2006.

[61] Wang, Y. On autonomous computing and cognitive processes. Proceedings of the Third IEEE International Conference on Cognitive Informatics (ICCl'04), USA, 2004.

[62] Wang, Y. Formal description of a set of meta cognitive processes of the brain. Proc. 6th IEEE Int. Conf. on Cognitive Informatics (ICCl'07), USA, 2007.

[63] Wang, Y. On cognitive informatics foundations of knowledge and formal knowledge systems. Proc. $6^{\text {th }}$ IEEE Int. Conf. on Cognitive Informatics (ICCl'07), USA, 2007.

[64] Wang, Y.; Liu, D.; Ruhe, G. Formal description of the cognitive process of decision making. Proceedings of the Third IEEE International Conference on Cognitive Informatics (ICCl'04), USA, 2004.

[65] Wiener, N. Cibernética o el Control y la Comunicación en Animales y Máquinas. España: Tusquets, 1985. (2 Edición).

[66] Yager, R. On ordered weighted averaging aggregation operators in multi-criteria decision making. IEEE Trans. On Systems, Man and Cybernetics, USA, v. 18, p. 183-190, 1988.

[67] Yager, R. Families of OWA operators. Fuzzy Sets and Systems, v. 59, p. 125-148, 1993.

[68] Yager, R.; Kacprzyk, J. The Ordered Weighted Averaging Operators: Theory And Applications. USA: Kluwer Academic Publishers, 1997.

[69] Yager, R.; Pasi, G. Modelling majority opinion in multi-agent decision making. International Conference on Information Processing and Management of Uncertainty in Knowledge-based Systems, 2002.

\section{Author' biography with Photo}

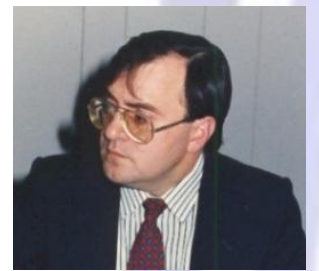

David L. La Red Martínez (Corresponding Author): Expert in Statistics and Computing, 1979, Northeast National University, Argentine; Master's degree in Computer Science and Informatic 2001, Northeast National University, Argentine, under an agreement with the University of Cantabria, Spain; University Teaching Specialist, 2003, Northeast National University, Argentine; PhD in Systems and Computer Engineering, 2011, University of Malaga, Spain; Professor of the Northeast National University, National Technological University and Chaco Austral National University, Argentina; research areas: operating systems, data communications, decision-making systems, aggregation operators, data mining, academic performance.

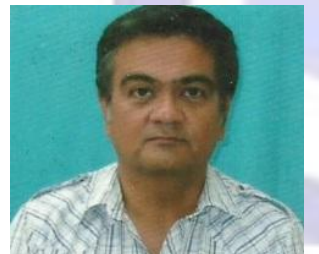

Julio C. Acosta: Construction Engineer, 1986, Northeast National University, Argentine; Master in Methodology of Scientific Research, 2013, Lanus National University, Argentina; Professor of Northeast National University, Argentine, Argentina; research areas: operating systems, distance learning, ICT in education, data mining, academic performance. 